\title{
Myasthenia gravis: further electrophysiological and ultrastructural analysis of transmission failure in the mouse passive transfer model
}

\author{
K . V . T O Y K A, K . L . B I R N B E R G E R, A . P . A N Z I L, \\ C. SCHLEGEL, U. BES I NGER, A N D A. STR UPPLER \\ From the Department of Neurology, Technical University, School of Medicine and the \\ Max-Planck-Institute for Psychiatry, Munich, West Germany
}

SUM MARY Using the mouse passive transfer model the mean amplitude of miniature endplate potentials and endplate potentials of mice treated with myasthenic immunoglobulins was markedly decreased. Miniature endplate potential frequency and quantum content of endplate potentials were normal, arguing against a major presynaptic disarrangement. Under electronmicroscopy no gross structural alterations of endplates were demonstrated. It is concluded that the mouse passive transfer model closely resembles human myasthenia gravis of recent onset.

Myasthenia gravis is a neuromuscular disease characterised by weakness and abnormal fatigability of skeletal muscle based on failure of neuromuscular transmission. The cause of the transmission failure has long been thought to lie in the presynaptic nerve terminal of the neuromuscular junction (Elmqvist et al., 1964). Recently, however, a large body of evidence has accumulated pointing to the postsynaptic membrane as the site of the defect. The findings indicate a reduced number of receptors available for bungarotoxin binding at the endplate region (Fambrough et al., 1973; Engel et al., 1977a). It has been shown that the reduced sensitivity of myasthenic muscle endplates to microiontophoretically applied acetylcholine (Albuquerque et al., 1976), as well as the decreased bungarotoxin binding, can be accounted for by either loss or damage of receptors, or their occlusion by some other agent to which they will bind (Engel et al., $1977 \mathrm{a}, \mathrm{b})$. Structural alterations of the postsynaptic muscle membrane (Engel and Santa, 1971) may also interfere with transmitter diffusion to the receptor or with the receptor itself.

Several lines of evidence now suggest that the reduction in receptor availability involves a

Presented in part at the Eleventh World Congress of Neurology, Amsterdam, 1977.

Address for reprint requests: Dr K. V. Toyka, Neurol. Klinik, Moehlstr. 28, 8 Muenchen 80, West Germany.

Accepted 6 April 1978 humorally mediated autoimmune reaction against the ACh-R:

1. Immunisation of animals including primates with purified ACh-R results in a myasthenialike disease (experimental autoimmune myasthenia gravis) (Patrick and Lindstrom, 1973; Green et al., 1975; Tarrab-Hazdai et al., 1975; Granato et al., 1976; Sanders et al., 1976).

2. Antibodies against ACh-R were demonstrated in the serum of patients with myasthenia gravis in vitro (Almon et al., 1974; Aharonov et al., 1975; Bender et al., 1975; Lindstrom et al., 1976a; Mittag et al., 1976) using various techniques.

3. Passive transfer of immunoglobulin $G$ from patients with myasthenia gravis to mice reproduces typical features of the disease (mouse passive transfer model) (Toyka et al., 1975, 1977).

4. Incubation of cultured fetal muscle cells with myasthenic immunoglobulins results in an accelerated degradation of ACh-R (Appel et al., 1977; Kao and Drachman, 1977), and to a reduction in acetylcholine sensitivity in vitro (Anwyl et al., 1977; Bevan et al., 1977).

5. Immunoglobulin-like particles (Rash et al., 1976), and more recently IgG and C3 (Engel et al., 1977b), have been located by electronmicroscopical examination at the endplate membrane in human myasthenic muscle. 
A question of interest is what specific defects of neuromuscular transmission develop in an experimental animal not producing antibodies against its own ACh-R but injected with immunoglobulin from myasthenic humans. We also wished to know whether treatmant of the clinical disease would alter the response of mice injected with the patients' immunoglobulins.

The present studies confirm the electrophysiological similarities between human myasthenia gravis, experimental autoimmune myasthenia gravis, and the mouse passive transfer model. We also find that the efficacy of myasthenic immunoglobulin in producing defective neuromuscular transmission in the mouse is not predictable from the severity of the clinical disease.

\section{Patients and methods}

Thirteen patients (five female, eight male) with the diagnosis of myasthenia gravis-established by criteria used previously (Toyka et al., 1975, 1977)-gave informed consent for withdrawal of up to $200 \mathrm{ml}$ of blood. Ten patients with diseases other than myasthenia gravis were used as individual controls (Table 1).
PREPARATION OF THE IMMUNOGLOBULIN (IG) FRACTION

The immunoglobulin fractions were prepared by sterile ammonium sulphate precipitation at $33 \%$ saturation as described previously (Toyka et al., 1975, 1977). Dialysis was carried out three times against Ringer's solution. The IgG concentration in the dialysed crude Ig fraction was 1000 to 3000 $\mathrm{mg}$ per $100 \mathrm{ml}$ as measured by single radial immunodiffusion (RID, Behringwerke).

\section{INJECTION OF MICE}

Thirty female B6D2 $F_{1} / J$ mice (Jackson Laboratories, Maine, USA) were injected daily with the Ig fraction of an individual patient for up to 12 days. The amount of IgG injected was $12-20 \mathrm{mg}$ per day. The animals were immunosuppressed by a single dose of cyclophosphamide $(300 \mathrm{mg}$ per $\mathrm{kg}$ body weight) on day 2 . Levels of human IgG were measured in the mouse serum at the end of the experimental period. They ranged from 800 to $1200 \mathrm{mg}$ per $100 \mathrm{ml}$ which is equivalent to the concentration in normal human serum.

ANALYSIS OF TRANSMISSION AT THE NEUROMUSCULAR JUNCTION

At the end of the experimental period the mice

Table 1 Clinical and electrophysiological correlations

\begin{tabular}{|c|c|c|c|c|c|c|c|}
\hline \multirow{2}{*}{$\begin{array}{l}\text { Case } \\
\text { number }\end{array}$} & \multicolumn{7}{|c|}{ Clinical and electrophysiological correlations } \\
\hline & Sex & $\operatorname{Age}(y r)$ & $\begin{array}{l}\text { Duration of } \\
\text { disease }(y r)\end{array}$ & Clinical classification* & $\begin{array}{l}\text { Decremental } \\
\text { response } \dagger\end{array}$ & Treatment + & $\begin{array}{l}\text { MEPP amplitude } \\
\text { in mice }(m V) \S\end{array}$ \\
\hline \multicolumn{8}{|c|}{ Myasthenic patients } \\
\hline 1 & $\mathrm{~F}$ & 43 & 2 & II B & $\div$ & Mest, Pred & 0.35 \\
\hline 2 & $\mathbf{F}$ & 18 & $1 / 5$ & II A & + & - & 0.53 \\
\hline 3 & $\mathbf{F}$ & 31 & $1 / 2$ & II A & 0 & Mest & 0.44 \\
\hline 4 & $\mathrm{~F}$ & 35 & 15 & II B & $\therefore$ & Thx, Aza, Mest & 0.53 \\
\hline 5 & $F$ & 22 & $3 / 2$ & II B & + & Thx, Mest & 0.46 \\
\hline 6 & $\mathbf{M}$ & 47 & 14 & IV & + & Thx, Mest, Pred & 0.26 \\
\hline 7 & $\mathbf{M}$ & 48 & 1 & III & $\div$ & Thx, Mest, Pred, Aza & $0.33 \|$ \\
\hline 8 & $\mathbf{M}$ & 76 & $1 / 5$ & II B & ND & Mest & 0.44 \\
\hline 9 & $\mathbf{M}$ & 26 & 4 & II A & $\therefore$ & Thx, Mest & 0.34 \\
\hline 10 & $\mathbf{M}$ & 62 & 16 & $11 \mathrm{~A}$ & 0 & Mest & 0.28 \\
\hline 11 & $\mathbf{M}$ & 32 & 5 & III & + & Thx, Mest & $0.31 \|$ \\
\hline 12 & $\mathbf{M}$ & 73 & $1 / 2$ & II A & $\div$ & - & 0.28 \\
\hline 13 & $\mathbf{M}$ & 44 & 5 & II A & $\therefore$ & - & 0.26 \\
\hline \multicolumn{8}{|c|}{ Control subjects } \\
\hline 14 & $\mathbf{M}$ & 32 & 10 & Myoblastoma & ND & - & 0.80 \\
\hline 15 & $\mathbf{M}$ & 22 & 1 & Polymyositis & ND & Pred, Aza & 0.91 \\
\hline 16 & $\mathrm{~F}$ & 19 & $1 / 5$ & Dermatomyositis & ND & Pred, Aza & 0.66 \\
\hline 17 & $\mathrm{~F}$ & 57 & 5 & Polymyositis & ND & Pred, Aza & 0.75 \\
\hline 18 & $\mathrm{~F}$ & 37 & 20 & Lupus erythematosus & ND & Pred, Aza & 0.49 \\
\hline 19 & $\mathrm{~F}$ & 42 & 6 & Lupus erythematosus & ND & Pred, Aza & $0.68 \|$ \\
\hline 20 & $F$ & 50 & $1 / 2$ & Polyneuropathy & ND & - & 0.69 \\
\hline 21 & $\mathbf{M}$ & 73 & 2 & Polymyositis & ND & Pred, Aza & 0.63 \\
\hline 22 & $\mathrm{~F}$ & 56 & 5 & Amyotrophic lateral sclerosis & ND & - & 0.76 \\
\hline 23 & $\mathbf{M}$ & 51 & 1 & Mediastinal cyst & 0 & -- & $0.73^{\circ}$ \\
\hline
\end{tabular}

*Based on Osserman's clinical classification; tindicates decrement of more than $10 \%$ at stimulation rate of 2 or $5 \mathrm{~Hz}$; ND= not determined; + Mest $=$ pyridostigmine (Mestinon); Thx =thymectomy; Pred = prednisone; Aza =azathioprine; $\$$ mean MEPP amplitude in diaphragms injected $w$;ith the individual immunoglobulin fraction; $\|$ mean of two experiments; 1 mean of three experiments. 
were anaesthetised with pentobarbitone $(60-70 \mathrm{mg}$ per kg body weight). From each animal the left hemidiaphragm was removed, preserving a $1 \mathrm{~cm}$ stump of the left phrenic nerve. It was then transferred rapidly to a modified Liley's solution containing $10 \mathrm{mmol}$ magnesium per litre and gassed with $95 \% \mathrm{O}_{2} / 5 \% \mathrm{CO}_{2}$. The diaphragm was pinned at resting length in a flow-chamber on a piece of silicone rubber and left to equilibrate for at least $30 \mathrm{~min}$. Temperature was maintained at $31^{\circ} \mathrm{C}$. Stimulation of the phrenic nerve was carried out through a suction electrode by a Grass $\mathbf{S} 88$ stimulator at $3 \mathrm{~Hz}(0.2 \mathrm{~ms}, 5-7 \mathrm{~V})$. Intracellular recordings were made with conventional microelectrodes filled with $3 \mathrm{M} \mathrm{KCL} \mathrm{(4-12} \mathrm{M} \Omega$ ). The electrical signals were amplified by a WPI M4A preamplifier and displayed on a Tektronix storage oscilloscope. Recordings were made on a Siemens Mingograph (frequency range $0-1000 \mathrm{~Hz}$ ). The membrane resting potentials (MRP) of all cells were measured and only cells with MRPs over $-60 \mathrm{mV}$ at the end of the recording period were used. Fifteen to 20 miniature endplate potentials (MEPP) with rise times less than $1 \mathrm{~ms}$ were measured per muscle fibre, and the amplitude was then corrected to a MRP of $-75 \mathrm{mV}$. Miniature endplate potential frequencies were also recorded in each muscle fibre. Electrical stimulation of the phrenic nerve was performed in $\mathbf{2 3}$ of the $\mathbf{3 0}$ diaphragms. Thirty or more endplate potentials (EPP) were recorded and the last 20 were measured. The mean amplitudes of MEPP and EPP and the mean MEPP frequency were calculated for each fibre, and these mean values were used to calculate the grand mean for all fibres in each diaphragm (usually 12 to 20 per diaphragm). The average quantum content of EPP was estimated according to the formula (Boyd and Martin, 1956)

$$
\text { quantum content }(\mathrm{m})=\frac{\text { mean EPP amplitude }}{\text { mean MEPP amplitude }}
$$

No correction was made for nonlinearity as EPP amplitudes were usually small.

Statistical analysis was carried out using the nonparametric Wilcoxon test (Diem and Lentner, 1968). $P$ values smaller than 0.05 were considered significant.

PREPARATION OF MUSCLE SPECIMEN FOR ELECTRONMICROSCOPIC EXAMINATION

Strips of diaphragms were fixed with fresh cold $2.5 \%$ glutaraldehyde in $0.1 \mathrm{M}$ cacodylate, $\mathrm{pH}$ 7.2. The regions known to be rich in motor endplates were trimmed down to blocks $1 \mathrm{~mm}$ of edge. The blocks were washed overnight in buffer, postfixed with $\mathrm{OsO}_{4}$, and embedded in epoxy resin. Ultrathin sections were cut with an LKB microtome, double stained with uranyl acetate and lead citrate, viewed with a Zeiss 9A electron microscope, and photographed at primary magnifications ranging between $\times 1900$ and $\times 41000$. About 250 serial and random sections from 20 to 30 endplates were examined.

\section{Results}

The amplitudes of miniature endplate potentials in control animals ranged from $0.50 \mathrm{mV}$ to $0.91 \mathrm{mV}$ with a mean of $0.71 \mathrm{mV}$. The range of EPP amplitudes was $0.50 \mathrm{mV}$ to $0.85 \mathrm{mV}$ with a mean of $0.74 \mathrm{mV}$.

The main abnormalities in mice injected with myasthenic immunoglobulins were a $48 \%$ reduction of MEPP amplitudes $(P<0.005)$ and a $33 \%$ reduction of EPP amplitudes $(P<0.01)$, as shown in Figs. 1 and 2. Mean quantum content of EPPs and the membrane resting potentials (MRP) were not significantly different in the two groups (Table 2). The mean MEPP frequency appeared to be decreased in the myasthenic diaphragms by $25 \%$, but in fibres with small MEPPs a greater proportion of these potentials was obscured by the background noise (usually 100-150 $\mu \mathrm{V}$ ). When electrodes with a particularly favourable signal-to-

MINIATURE EPPS

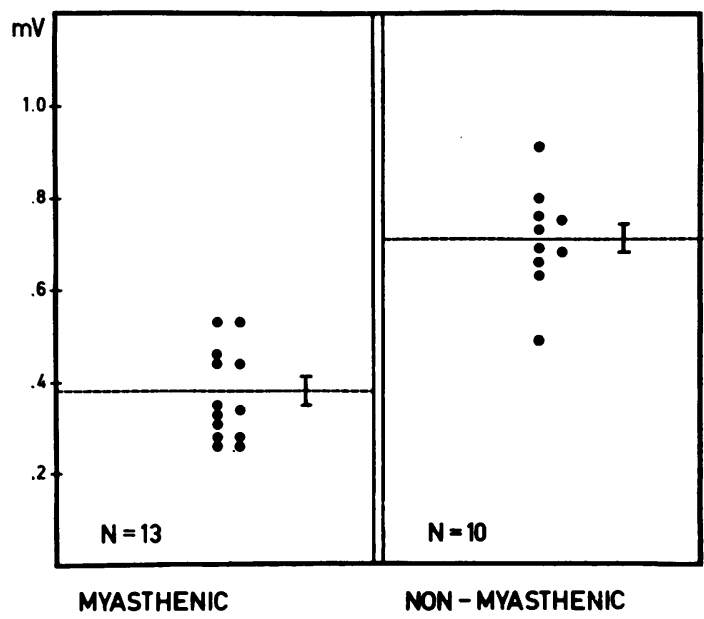

Fig. 1 Amplitudes of miniature endplate potentials $(\mathrm{mV})$ in mice treated with immunoglobulin fractions from patients. Each data point represents the mean amplitude of a diaphragm. Five of the data points are means of duplicate or triplicate experiments.

Horizontal bar indicates the arithmetic mean, vertical bar the standard error of the mean. $N=$ number of patients. 
EPPs

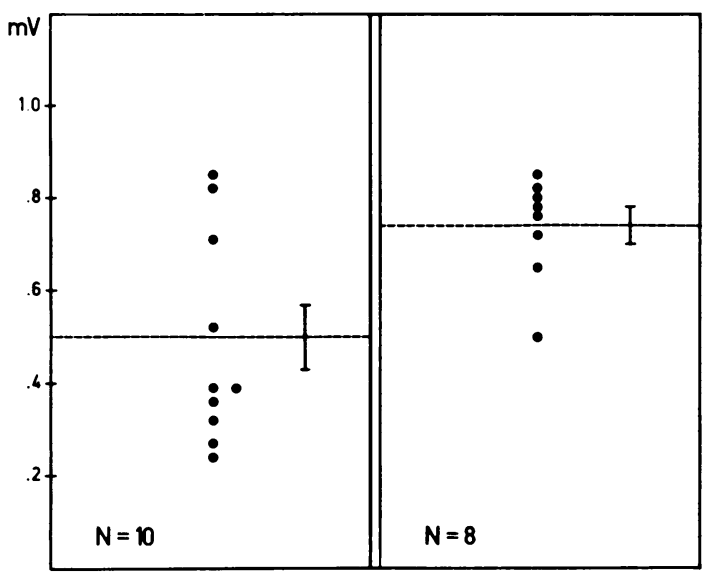

MYASTHENIC

NON - MYASTHENIC
Fig. 2 Amplitudes of endplate potentials $(m V)$ in mice treated with immunoglobulin fractions. Each data point represents the mean of one diaphragm. Horizontal bar indicates the arithmetic mean, vertical bar the standard error of the mean. $N=$ number of patients.

Table 2 Mean values \pm standard error of the mean of membrane resting potentials $(M R P,-m V), M E P P$ frequency $\left(\mathrm{sec}^{-1}\right)$, and quantum content of EPPs in $10 \mathrm{mM} \mathrm{Mg}$ solution. Diaphragms of mice treated with immunoglobulin fractions from patients with myasthenia gravis or non-myasthenic diseases

\begin{tabular}{llll}
\hline Treatment & $M R P$ & $\begin{array}{l}\text { MEPP } \\
\text { frequency }\end{array}$ & $\begin{array}{l}\text { Quantum content } \\
\text { of EPPs (at 3 Hz } \\
\text { stimulation })\end{array}$ \\
\hline $\begin{array}{c}\text { Myasthenic } \\
\text { immunoglobulins }\end{array}$ & $\begin{array}{l}74.7 \pm 0.7 \\
(\mathrm{~N}=15)\end{array}$ & $\begin{array}{l}1.5 \pm 0.25 \\
(\mathrm{~N}=15)\end{array}$ & $\begin{array}{l}1.2 \pm 0.05 \\
\mathrm{~N}=12)\end{array}$ \\
$\begin{array}{c}\text { Control } \\
\text { immunoglobulins }\end{array}$ & $\begin{array}{l}75.6 \pm 0.6 \\
(\mathrm{~N}=13)\end{array}$ & $\begin{array}{l}1.9 \pm 0.50 \\
(\mathrm{~N}=13)\end{array}$ & $\begin{array}{l}1.1 \pm 0.10 \\
(\mathrm{~N}=12)\end{array}$ \\
P value & $\mathrm{NS}$ & $<0.05$ & $\mathrm{NS}$ \\
\hline
\end{tabular}

$\mathrm{N}=$ number of diaphragms tested. $\mathrm{P}$ values calculated by Wilcoxon test, $\mathbf{N S}=$ not significant.

noise ratio were used MEPP frequency was in the same order of magnitude as in controls. A similar phenomenon has been observed in human myasthenia gravis (Rash et al., 1976).

In 11 of 13 tested patients transfer of the immunoglobulin fraction caused a lowering of the average miniature endplate potential below the lowest control value $(0.50 \mathrm{mV})$ (Table 1$)$. In two experiments we found an average MEPP amplitude of $0.53 \mathrm{mV}$, which was in the lower range of the control values. In the present series all of eight sera from male patients and three of five females gave a positive result. Two mice injected with the serum of one patient (number 6) showed mild clinical signs of muscle weakness with dragging gait and reduced strength of the forelimbs when holding on to the grid of the cage. Neither the remaining myasthenic sera nor any of the control sera caused similar signs in any animal.

We were unable to demonstrate a clear-cut correlation in our material between MEPP amplitudes in the test preparations and the clinical conditions of the patients from whom the serum was obtained. For example patient 10 was clinically in almost complete remission, but his serum produced a definite lowering of MEPP amplitude, while serum from clinically more affected patients of ten produced only a moderate reduction (patient 8 ) or no decrease at all (patient 4).

Electronmicroscopical examination of serial and random sections of the endplates of two markedly affected diaphragms after treatment with myasthenic immunoglobulins revealed essentially normal nerve and muscle junctional components (Fig. 3). In a number of endplates some regions of the postsynaptic membrane showed electron-dense material the density of which approximates that of the inner part of the basal membrane. It appeared as a series of five to 10 variably shaped spikelets located at the tips of the synaptic folds measuring $50-150 \AA$ in length and up to $50 \AA$ in width and abutting on the outer surface of the postsynaptic membrane (Fig. 3, inset). In a few control endplates similar material was also observed.

\section{Discussion}

In confirmation of previous reports it was shown in the present series of experiments that transfer of the immunoglobulin fraction of sera from myasthenic patients to mice produces electrophysiological and, in some animals, clinical signs similar to those found in the human disorder.

The average endplate potential amplitude in animals treated with $\mathrm{Ig}$ was reduced by $33 \%$, the average miniature endplate potential amplitude by $48 \%$. The quantum content of each EPP was, therefore, not significantly changed compared to healthy animals (Table 2). Miniature endplate potential frequency-another indicator of presynaptic function (Hubbard et al., 1969) - was not grossly changed in myasthenic animals.

Similar results have been obtained in human myasthenia gravis (Elmqvist et al., 1964; Albuquerque et al., 1976; Rash et al., 1976) and in the chronic phase of experimental autoimmune myasthenia gravis in rats (Lambert et al., 1976). In human myasthenic muscle a decreased junctional sensitivity to ACh has recently been demonstrateo 


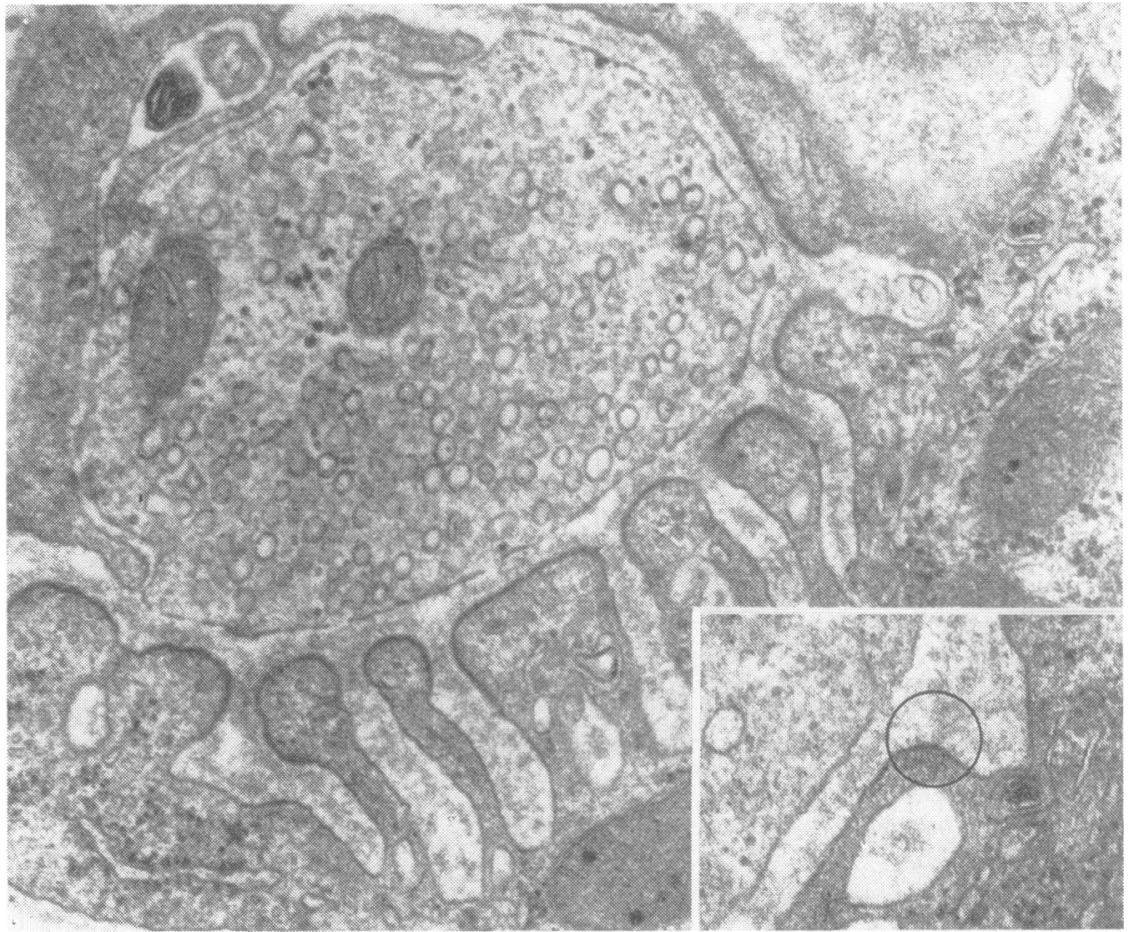

Fig. 3 Endplate of a mouse diaphragm after passive transfer of human myasthenic immunoglobulin. This essentially normal profile is representative of many neuromuscular junctions: the material in the junctional cleft is of medium to low density, being generally densest equidistant between the opposing cell surfaces. $\times 54000$. Inset: detail of another normal looking endplate: an orderly series of spikelets (circle) project from the outer surface of the postsynaptic membrane into the primary cleft. $\times 72000$.

adding support to the concept of a postsynaptic defect in myasthenia gravis, which had earlier been proposed on the basis of a decreased number of bungarotoxin binding sites (Fambrough et al., 1973). Except for ACh sensitivity which was not measured by us in these experiments, all parameters of the MPTM are in good agreement with those reported for human myasthenia gravis and chronic experimental autoimmune myasthenia gravis. Unless heterogeneous and homogeneous immunoglobulins have different actions at the neuromuscular junction we think it likely that a postsynaptic effect explains our findings.

By contrast, in the acute phase of experimental autoimmune myasthenia gravis (Lambert et al., 1976), or after passive transfer of serum from rats with the chronic form of this disease to normal recipient animals (Lindstrom et al., 1976a), the quantum content of EPPs and MEPP frequency are greatly reduced thus adding a presynaptic component to the transmission failure in these animals.
In humans with myasthenia gravis no equivalent phenomenon has yet been observed.

We find that serum from male and female patients was equally active on mouse preparations, and we, therefore, do not favour the hypothesis that the pathogenetic mechanism is basically different in male and female myasthenic patients (Feltkamp et al., 1974; Pirskanen, 1976). This does not rule out the possibility that genetic factors may play an important role at an earlier stage of the autoimmune process (Wekerle and Ketelsen, 1977).

The data indicate that the presence or absence of the "myasthenogenic" immunoglobulin is not clearly related to the mode and duration of treatment. The percentage of a positive mouse passive transfer assay was not different in thymectomised and nonthymectomised patients, nor did medication with immunosuppressive agents in the patients influence the ratio of positive results. It appears that the mouse transfer assay is correlated only 
with the presence of signs of generalised myasthenia gravis. Further studies dealing with myasthenia gravis patients in complete remission with or without medication are needed to evaluate this correlation in greater detail.

The bioassay appears to be specific for myasthenia gravis as judged by the individual disease controls in this study.

The in vitro assay of binding antibodies against ACh-R extracted with detergent from human or mammalian muscle has been reported to be slightly more sensitive than the in vivo mouse response and highly specific for myasthenia gravis (Lindstrom et al., 1976b). However, tests measuring antibodies which block bungarotoxin binding to ACh-R are much less sensitive (Almon et al., 1974; Lindstrom et al., 1976b; Mittag et al., 1976). The variation in the sensitivity may in part be due to the difference in the physicochemical properties of the ACh-R after being disrupted from the junctional membrane with detergent (Changeux et al., 1976; Lennon, 1976).

Other differences in the model system response may indicate variations in the cross-reactivity between myasthenic Ig and receptors from different mammalian species (mouse versus rat versus human muscle). The fact that human "myasthenogenic" immunoglobulins act across a species barrier demonstrates that both human and mouse ACh-R share a sufficient number of antigenbinding sites at or close to the ACh-binding site to allow for a decrease in the response to the transmitter.

Preliminary evidence from a limited number of endplates from clearly affected diaphragms after passive transfer of myasthenic immunoglobulins indicates that no gross abnormality can be demonstrated. The endplates in these muscles do not look like those from patients with chronic myasthenia gravis (Engel and Santa, 1971) or from rats with chronic experimental autoimmune myasthenia gravis (Engel et al., 1976) under the electronmicroscope. They resemble rather the ultrastructural findings described in patients with myasthenia gravis of recent onset (Rash et al., 1976; Engel et al., 1977a) where the authors found virtually normal junctional components despite markedly decreased MEPP amplitudes. The linear densities we have observed in some endplates of the affected diaphragms but, on occasion, also in control endplates, seem to be nonspecific. Similarly shaped material has been demonstrated in rabbits with experimental autoimmune myasthenia gravis and in control animals (Thornell et al., 1976).

At present our findings indicate that the alterations in the mouse passive transfer model may closely resemble human myasthenia gravis of recent onset at a stage before irreversible structural damage has occurred. This hypothesis gains indirect support from earlier experimental observations in the mouse passive transfer model (Toyka and Pestronk, unpublished) that both reduced MEPP amplitudes and ACh-R binding to bungarotoxin may return towards normal values three to four weeks after treatment with immunoglobulins has been stopped, indicating the reversibility of the transmission defect. The exact nature of the mechanism of the interactions between myasthenic antibodies and ACh-receptors still remains to be determined. Recent evidence from in vitro studies using cultured rat muscle cells supports the view that antibodies block transmission by increasing the rate of degradation of receptor molecules (Anwyl et al., 1977; Appel et al., 1977; Bevan et al., 1977; Kao and Drachman, 1977). This does not necessarily imply a similar mechanism in junctional ACh-R of intact endplates.

The fact that the mouse passive transfer model combines a marked neurophysiological defect with lack of gross structural alterations makes it a suitable tool for studies on the myasthenic transmission failure.

We are indebted to Dr J. Dudel, Dr W. W. Hofmann, and Dr R. Rüdel for helpful discussions and for reviewing the manuscript.

\section{References}

Aharonov, A., Abramsky, O., Tarrab-Hazdai, R., and Fuchs, S. (1975). Humoral antibodies to acetylcholine receptor in patients with myasthenia gravis. Lancet, 2, 340-342.

Albuquerque, E. X., Rash, J. E., Mayer, R. F., and Satterfield, J. R. (1976). An electrophysiological and morphological study of the neuromuscular junction in patients with myasthenia gravis. Experimental Neurology, 51, 536-563.

Almon, R. R., Andrew, C. G., and Appel, S. H. (1974). Serum globulin in myasthenia gravis: inhibition of $a$-bungarotoxin binding to acetylcholine receptors. Science, 186, 55-57.

Anwyl, R., Appel, S. M., and Narahashi, T. (1977). Myasthenia gravis serum reduces acetylcholine sensitivity in cultured rat myotube. Nature, 267, 262-263.

Appel, S. H., Anwyl, R., McAdams, M. W., and Elias, S. (1977). Accelerated degradation of acetylcholine receptor from cultured rat myotubes with myasthenia gravis sera and globulins. Proceedings of the National Academy of Sciences USA, 74, 2130-2134.

Bender, A. N., Ringel, S. P., Engel, W. K., Daniels, M. P., and Vogel, Z. (1975). Myasthenia gravis: a 
serum factor blocking acetylcholine receptors of the human neuromuscular junction. Lancet, 1, 607-609.

Bevan, S., Kullberg, R. W., and Heinemann, S. F. (1977). Human myasthenic sera reduce acetylcholine sensitivity of human muscle cells in tissue culture. Nature, 267, 263-265.

Boyd, I. A., and Martin, A. R. (1956). The end-plate potential in mammalian muscle. Journal of Physiology, 132, 74-91.

Changeux, J. P., Benedetti, L., Bourgeois, J. P., Brisson, A., Cartaud, J., Devaud, P., Grünhagen, H., Moreau, M., Popot, J. L., Sobel, A., and Weber, M. (1976). Some structural properties of the cholinergic receptor protein in its membrane environment relevant to its function as a pharmacological receptor. In The Synapse, Cold Spring Harbor Symposium on Quantitative Biology, 211-230.

Diem, K., and Lentner, C. (1968). Documenta Geigy, Wissenschaftliche Tabellen, 7. Auflage. J. R. Geigy SA: Basel.

Elmqvist, D., Hofmann, W. W., Kugelberg, J., and Quastel, D. M. M. (1964). An electrophysiological investigation of neuromuscular transmission in myasthenia gravis. Journal of Physiology, 174, 417434.

Engel, A. G., and Santa, T. (1971). Histometric analysis of the ultrastructure of the neuromuscular junction in myasthenia gravis and the myasthenic syndrome. Annals of the New York Academy of Sciences, 183, 46-63.

Engel, A. G., Tsujihata, M., Lindstrom, J. M., and Lennon, V. A. (1976). The motor end-plate in myasthenia gravis and in experimental autoimmune myasthenia gravis. A quantitative ultrastructural study. Annals of the New York Academy of Sciences, 274, 60-79.

Engel, A. G., Lindstrom, J. M., Lambert, E. H., and Lennon, V. A. (1977a). Ultrastructural localization of the acetylcholine receptor in myasthenia gravis and in its experimental autoimmune model. Neurology (Minneapolis), 27, 307-315.

Engel, A. G., Lambert, E. H., and Howard, F. M. (1977b). Immune complexes (IgG and C3) at the motor end-plate in myasthenia gravis: ultrastructural and light microscopic localization and electrophysiologic correlations. Mayo Clinic Proceedings, 52, 267-280.

Fambrough, D. M., Drachman, D. B., and Satyamurti, S. (1973). Neuromuscular junction in myasthenia gravis: decreased acetylcholine receptors. Science, 182, 293-295.

Feltkamp, T. E. W., Berg-Loonen van den P. M., Nijenhuis, L. E., Engelfried, C. P., Rossum van A. L., Loghem van J. J., and Oosterhuis, H. J. G. H. (1974). Myasthenia gravis, autoantibodies and HL-A antigens. British Medical Journal, 1, 131-133.

Granato, D. A., Fulpius, B. W., and Moody, J. F. (1976). Experimental myasthenia in Balb/c mice immunized with rat acetylcholine receptors from rat denervated muscle. Proceedings of the National Academy of Sciences USA, 73, 2872-2876.
Green, D. P. L., Miledi, R., and Vincent, A. (1975). Neuromuscular transmission after immunization against acetylcholine receptors. Proceedings of the Royal Society, London B, 189, 57-68.

Hubbard, J. I., Llinás, R., and Quastel, D. M. J. (1969). Electrophysiological Analysis of Synaptic Transmission. Edward Arnold: London.

Kao, I., and Drachman, D. B. (1977). Myasthenic immunoglobulin accelerates acetylcholine receptor degradation. Science, 196, 527-529.

Lambert, E. H., Lindstrom, J. M., and Lennon, V. A. (1976). End-plate potentials in experimental autoimmune myasthenia gravis in rats. Annals of the New York Academy of Sciences, 274, 300-318.

Lennon, V. A. (1976). Immunology of the acetylcholine receptor. Immunological Communications, 5, 323-344.

Lindstrom, J. M., Engel, A. G., Seybold, M. E., Lennon, V. A., and Lambert, E. H. (1976a). Pathological mechanisms in experimental autoimmune myasthenia gravis. II. Passive transfer of experimental autoimmune myasthenia gravis in rats with antiacetylcholine receptor antibodies. Journal of Experimental Medicine, 144, 739-753.

Lindstrom, J. M., Seybold, M. E., Lennon, V. A., Whittingham, S., and Duane, D. D. (1976b). Antibody to acetylcholine receptor in myasthenia gravis: prevalence, clinical correlates, and diagnostic value. Neurology (Minneapolis), 26, 10541059.

Mittag, T., Kornfeld, P., Tormay, A., and Woo, C. (1976). Detection of anti-acetylcholine receptor factors in serum and thymus from patients with myasthenia gravis. New England Journal of Medicine, 294, 691-694.

Patrick, J., and Lindstrom, J. (1973). Autoimmune response to acetylcholine receptor. Science, 180, 871-872.

Pirskanen, R. (1976). On the significance of HL-A and LD antigens in myasthenia gravis. Annals of the New York Academy of Sciences, 274, 451-460.

Rash, J. E., Albuquerque, E. X., Hudson, C. S., Mayer, R. F., and Satterfield, J. R. (1976). Studies of human myasthenia gravis: electrophysiological and ultrastructural evidence compatible with antibody attachment to acetylcholine receptor complex. Proceedings of the National Academy of Sciences USA, 73, 4584-4588.

Sanders, D. B., Schleifer, L. S., Eldefrawi, M. E., Norcross, N. L., and Cobb, E. E. (1976). An immunologically induced defect of neuromuscular transmission in rats and rabbits. Annals of the New York Academy of Sciences, 274, 319-336.

Tarrab-Hazdai, R., Aharonov, A., Silman, I., Fuchs, S., and Abramsky, O. (1975). Experimental autoimmune myasthenia induced in monkeys by purified acetylcholine receptor. Nature, 256, 128-130.

Thornell, L. E., Sjöström, M., Mattsson, C. H., and Heilbronn, E. (1976). Morphological observations on motor end-plates in rabbits with experimental myasthenia gravis. Journal of the Neurological Sciences, 29, 389-410. 
Toyka, K. V., Drachman, D. B., Pestronk, A., and Kao, I. (1975). Myasthenia gravis: passive transfer from man to mouse. Science, 190, 397-399.

Toyka, K. V., Drachman, D. B., Griffin, D. E., Pestronk, A., Winkelstein, J. A., Fischbeck, K. H., and Kao, I. (1977). Myasthenia gravis: study of humoral immune mechanisms by passive transfer to mice. New England Journal of Medicine, 296, 125131.

Wekerle, H., and Ketelsen, U. P. (1977). Intrathymic pathogenesis and dual genetic control of myasthenia gravis. Lancet, 1, 678-680. 